\title{
Personality in perspective: Judgmental consistency across orientations of the face
}

\author{
Nicholas O Rule, Nalini Ambady \\ Department of Psychology, Tufts University, 490 Boston Avenue, Medford, MA 02155, USA; \\ e-mail: Nicholas.Rule@tufts.edu
}

\section{Reginald B Adams Jr}

Pennsylvania State University, University Park, PA 16802, USA

Received 11 February 2009, in revised form 10 August 2009

\begin{abstract}
Though the psychological literature is replete with information about the perception of faces presented at a full-frontal view, we know very little about how faces are perceived-and impressions formed - when viewed from other angles. We tested impressions of faces at full-frontal, three-quarter, and profile views. Judgments of personality (aggressiveness, competence, dominance, likeability, and trustworthiness) and physiognomy (attractiveness and facial maturity) were significantly correlated across full-frontal, three-quarter, and profile views of male faces. When under time pressure, with only a $50 \mathrm{~ms}$ exposure to each face, the correlations for profile with full-frontal and three-quarter view judgments of personality (but not physiognomy) dropped considerably. However, judgments of the full-frontal and three-quarter faces were significantly correlated across the self-paced and $50 \mathrm{~ms}$ viewing durations. These findings therefore show that perceptions of full faces lead to relatively similar interferences across both viewing angle and time.
\end{abstract}

\section{Introduction}

Whether sitting on a park bench, passing on the street, or stealing glances in a bar, we are constantly forming impressions of others (Ambady et al 2000). These impressions are rarely based on head-on encounters. Rather, we use the information available to us, and our impressions are often based on glimpses of people in profile or other partial views.

There have been numerous studies on impressions from faces, usually as observed from frontal views (see Zebrowitz 1997). As a result, few of these studies have examined inferences made from limited information-such as partial views of the face. Most typically, what we know about judgments of others from their faces comes from examinations of the full-frontal view. In the current work, we explored inferences of personality from three-quarter and profile views of the face, as compared against full-frontal view (control).

Several previous studies have explored inferences of personality from individuals' faces. In one study, Zebrowitz et al (1993) found consensus in ratings of a multitude of personality (dominance, warmth, physical strength, honesty, shrewdness) and physiognomic (attractiveness and facial maturity) traits for White American, Black American, and Korean targets judged from frontal views of faces. In addition, they showed that these judgments were consistent across raters for perceivers from both cultures. In addition, Albright et al (1997) found that judgments of Big-5 personality traits (culture, conscientiousness, extraversion, agreeableness, and emotional stability) and attractiveness were judged consistently by both American and Chinese perceivers for faces from their own culture and extraversion and agreeableness were judged consistently across cultures.

Recently, judgments of personality from the face have been found to predict important outcomes. For example, judgments of competence from the face have been shown to successfully predict the outcome of American political elections (Todorov et al 2005). Similarly, judgments of power (as composed of competence, dominance, and 
facial maturity) from Chief Executive Officers' faces predicted the amount of profits that their companies made (Rule and Ambady 2008a, 2009).

Facial physiognomy can also influence perceptions of personality. Facial attractiveness exerts a particularly strong influence on the way in which individuals are perceived (Dion et al 1972; see Langlois et al 2000, for review). Attractiveness is associated with a halo effect by which attractive persons are perceived to possess positive qualities along other dimensions and unattractive persons are perceived to possess negative qualities (Griffin and Langlois 2006). The influence of facial attractiveness appears to occur non-consciously (van Leeuwen and Macrae 2004) and significantly impacts the way that we behave toward others (eg Clifford and Walster 1973).

Similarly, facial maturity influences personality attributions, as well. Persons with low facial maturity (eg large eyes, rounded features, a high brow ridge, non-prominent cheekbones, and full lips) are said to have faces that are reminiscent of infants (independent of age-Zebrowitz and Montepare 1992) and are thus referred to as 'babyfaced'. From an ecological perspective (eg Zebrowitz and Montepare 2006), we have arguably evolved innately prepared responses to babyish facial cues, ones that increase the probability of a baby's survival. Because such responses are thought to be 'hardwired', they have been hypothesized to be inadvertently generalized to contexts where such responses are explicitly not applicable. Supporting this view is research demonstrating that even adults with such features are perceived and treated much like infants (eg helpless, warm, kind, irresponsible), even to the extent that they are sometimes spoken to in 'baby-talk' (Berry and McArthur 1985; Zebrowitz et al 1992). This phenomenon is referred to as an 'overgeneralization effect' because the response has overgeneralized beyond its original class (eg babies) to a second class that is distinct but perceived to be similar (eg babyfaced adults - see Zebrowitz 1997). Conversely, those with high facial maturity (eg angular features, prominent cheekbones, and a low brow) are seen as highly capable, intentional, intelligent, and culpable (see Berry and Landry 1997). Facial maturity overgeneralization effects are independent of attractiveness (Zebrowitz and Montepare 1992) and together these two sets of physical features serve as excellent proxies for a plethora of personality judgments (ie Zebrowitz 1997).

Previous work on perceptions of faces at various angles has been primarily restricted to examining the effects of viewing angle on memory. Multiple studies have demonstrated that faces rotated on the vertical axis can be remembered when encoded and retrieved at different orientations (Busey and Zaki 2004), though these changes in viewing angle between encoding and retrieval can reduce recognition accuracy when the identities of the faces are unfamiliar to the perceivers (eg non-famous faces; see O'Toole et al 1998). Similarly, views of faces in profile severely limit perception across various tasks (Bruce et al 1987; Hill and Bruce 1996) and a three-quarter $\left(45^{\circ}\right)$ view has under some conditions been found to result in better recognition than either a profile $\left(90^{\circ}\right)$ or full-frontal view $\left(0^{\circ}\right.$; eg Bruce et al 1987), though this 'three-quarter advantage' may actually only be a three-quarter equivalence, as faces viewed at $0^{\circ}$ and $45^{\circ}$ may be recognized equally well (see McKone 2008). Moreover, it has been found that two different faces seen from the same view are more objectively similar than a single face seen at multiple views (Hill et al 1997). Patterson and Baddeley (1977) found that memory for faces presented at various viewing angles was better when following judgments of personality than when following judgments of physical features. To our knowledge, however, that is the extent to which inferences from the face, generally, and assessments of personality, specifically, have been studied from multiple visual perspectives of the face.

In this work we examined how judgments of personality and physiognomy may be affected by changes in view. We compared attributions to various personality and physiognomic traits when viewed at three different poses $\left(0^{\circ}, 45^{\circ}\right.$, and $\left.90^{\circ}\right)$. To do this, 
we chose several traits that have been found important for social judgments in past work. For judgments of physiognomy, we examined perceivers' impressions of attractiveness (eg Langlois et al 2000; Rhodes 2006) and facial maturity (eg Berry and Landry 1997; Zebrowitz 1997). For judgments of personality, we examined perceivers' impressions of competence (eg Rule and Ambady 2009; Todorov et al 2005), dominance and aggressiveness (eg Chiao et al 2008; Mazur 2005), and likeability and trustworthiness (eg Porter et al 2008; Todorov et al 2005). We compared judgments of these traits across viewing angles in study 1.

In addition, in study 2 we examined the effects of exposure time on the inferences made about these traits. Previous work has shown that our judgments of others may occur very early after perceiving their faces. For instance, Willis and Todorov (2006) found agreement between personality traits when viewed at both brief $(100 \mathrm{~ms})$ and extended (1000 ms) durations. Similarly, Bar et al (2006) reported that judgments of threat were consistent between presentations of faces for $39 \mathrm{~ms}$ and $1700 \mathrm{~ms}$. In both of these studies the faces were tested in the full-frontal view only; thus it remains a question whether viewing faces quickly from other angles might permit consistent judgments. Indeed, given that we often form first impressions of others quickly and with just passing glances, extending this work to additional viewing angles may extend the ecological validity of that past work. Additionally, consistency across viewing angles at both self-paced and speeded presentation durations can be informative for the processes that subserve trait inferences. The ability to make judgments efficiently (eg under temporally restricted durations) is regarded as a characteristic of automatic processes (Bargh 1994), and congruent outcomes at both long and very short speeds may suggest that the inferences are being formed automatically.

\section{Study 1}

Do our judgments when perceiving faces at $0^{\circ}$ agree with our judgments when perceiving faces at other angles? In study 1 this question was addressed by asking participants to judge faces at $0^{\circ}, 45^{\circ}$, and $90^{\circ}$ on several behavioral (aggressiveness, competence, dominance, likeability, and trustworthiness) and physiognomic (attractiveness and facial maturity) traits and then compared these judgments across orientations.

\subsection{Method}

2.1.1 Participants. Forty-eight undergraduates (twenty-five women; ages 18-22 years) participated for partial credit in an introductory psychology course. The experiment consisted of three versions to counterbalance the stimuli; equal numbers of participants were assigned to the three conditions.

2.1.2 Stimuli. Images were of fifty-nine Caucasian males, aged approximately $20-35$ years, photographed in gray-scale under conditions controlled for distance, angle, and luminosity [target gender was kept constant to conserve homogeneity and avoid the influence of gender stereotypes upon judgments-eg Hess et al (2005)]. Each target presented a neutral expression and was photographed at three angles: $0^{\circ}$ (full-frontal view), $45^{\circ}$ left (three-quarter view), and $90^{\circ}$ left (profile) - see figure 1 . Targets' faces, necks, and hair were visible in the photographs and all targets wore identical white shirts. No targets wore any jewelry or glasses and each image was $300 \times 300$ pixels in size presented on a $1024 \times 768$ pixel computer screen.

2.1.3 Procedure. Participants viewed each of the targets in random order and made self-paced judgments on a 7-point scale. Participants rated each target on five measures of personality (aggressiveness, competence, dominance, likeability, and trustworthiness) and two measures of physiognomy known to have pronounced influences on the perception of personality (attractiveness and babyfacedness/facial maturity). Each trait 


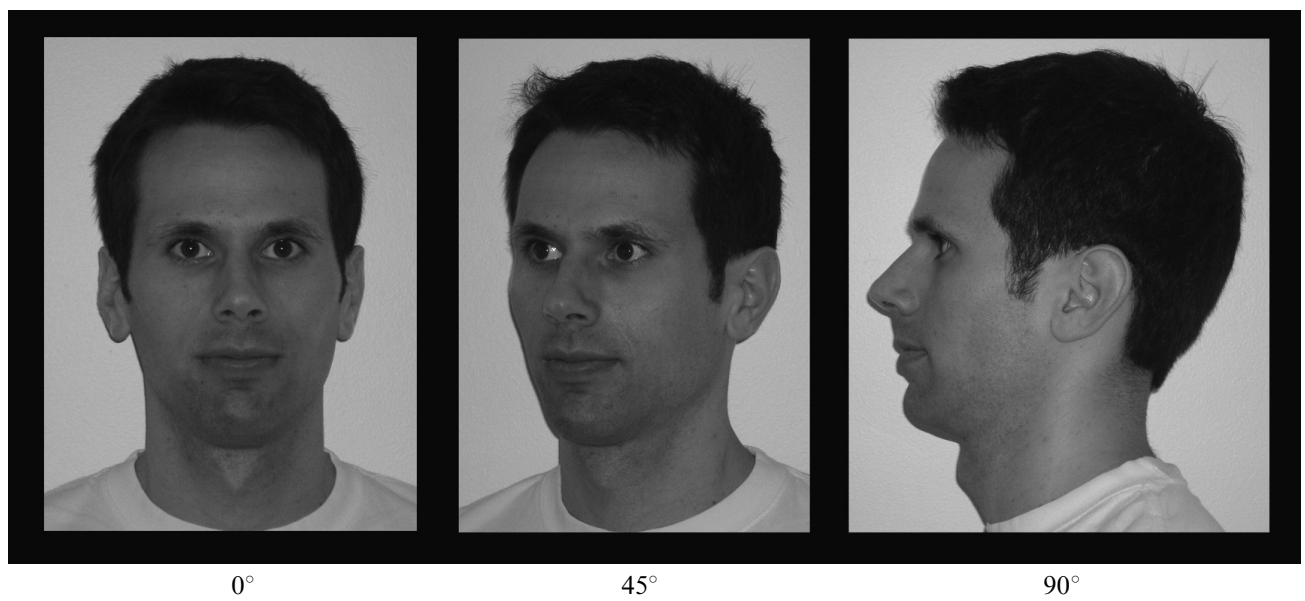

Figure 1. Example stimulus similar to that used in the actual studies showing a man's face at full-frontal $\left(0^{\circ}\right)$, three-quarter $\left(45^{\circ}\right)$, and profile $\left(90^{\circ}\right)$ viewing angles.

was presented by randomized blocks, and images were shown with both a question (eg "How trustworthy, would you say, this person is?") and scale [eg "Not at all trustworthy (1)" to "Very trustworthy (7)"] on each trial. The scales and anchors were analogous for each trait [ie "Not at all $X$ (1)" to "Very $X$ (7)"] and each face was shown once per block in a repeated-measures design. Participants' average response time in making these judgments was $1853 \mathrm{~ms}(\mathrm{SD}=1793 \mathrm{~ms})$.

Participants judged faces from each of the three conditions. The selection of which faces were presented from each condition, however, was counterbalanced in a Latinsquare design. This resulted in three versions of the experiment, such that participants in version $A$ rated faces $1-20$ at $0^{\circ}$, faces $21-40$ at $45^{\circ}$, and faces $41-59$ at $90^{\circ}$; participants in version B rated faces $21-40$ at $0^{\circ}$, faces $41-59$ at $45^{\circ}$, and faces $1-20$ at $90^{\circ}$; and participants in version $\mathrm{C}$ rated faces $41-59$ at $0^{\circ}$, faces $1-20$ at $45^{\circ}$, and faces $21-40$ at $90^{\circ}$. Thus, each participant saw only one viewing angle for each target and these photos were repeated seven times throughout the experiment (once for each trait) in a different random order every time.

\subsection{Results and discussion}

Our goal was to measure the extent to which participants' impressions of the faces were consistent across viewing angles. Judgments of targets were therefore averaged across participants; thus, faces served as the unit of analysis so that conclusions could be drawn about the faces, rather than the perceivers. Every target had twenty-one scores: one for each of the seven traits at the three orientations. The mean (acrossparticipant) scores for each face were aggregated according to orientation. All of the three sets of faces (from the three versions of the experiment) at $0^{\circ}$ were combined into a single vector, and the faces' companion scores at $45^{\circ}$ and $90^{\circ}$ were combined into separate vectors according to orientation, as well. We then inter-correlated the scores in these three vectors (ie $0^{\circ}: 45^{\circ}, 45^{\circ}: 90^{\circ}$, and $0^{\circ}: 90^{\circ}$ ) for each trait.

Participants' ratings of the faces were consistent across the three orientations for all seven traits (all $r \mathrm{~s}>0.30$, all $p \mathrm{~s}<0.05$; see table 1). That is, judgments of the targets at $0^{\circ}$ were significantly correlated with judgments of the targets at $45^{\circ}$ and $90^{\circ}$ for all seven traits. This suggests that the information perceivers use to form impressions about individuals with regard to aggressiveness, competence, dominance, likeability, trustworthiness, attractiveness, and facial maturity is consistent at full-frontal, threequarter, and profile views (table A1 in the appendix presents the inter-correlations between these seven traits at the three viewing angles). 
Table 1. Correlation coefficients for participants' self-paced judgments of targets between $0^{\circ}, 45^{\circ}$, and $90^{\circ}$ viewing orientations for each trait in study 1 (degrees of freedom $=57$ ).

\begin{tabular}{|c|c|c|c|c|c|c|}
\hline \multirow{2}{*}{$\begin{array}{l}\text { Viewing } \\
\text { orientations }\end{array}$} & \multicolumn{6}{|c|}{ Personality traits } \\
\hline & aggressiveness & competence & dominance & likeability & trustworthiness & $\bar{r}$ \\
\hline \multirow{5}{*}{$\begin{array}{l}0^{\circ}-45^{\circ} \\
45^{\circ}-90^{\circ} \\
0^{\circ}-90^{\circ}\end{array}$} & $0.64 * * *$ & $0.62 * * *$ & $0.62 * * *$ & $0.49 * * *$ & $0.67 * * *$ & 0.61 \\
\hline & $0.49 * * *$ & $0.47 * * *$ & $0.59 * * *$ & $0.51 * * *$ & $0.38 * *$ & 0.49 \\
\hline & $0.47 * * *$ & $0.40 * *$ & $0.49 * * *$ & $0.47 * * *$ & $0.43 * * *$ & 0.45 \\
\hline & \multicolumn{3}{|c|}{ Physiognomic traits } & \multicolumn{2}{|c|}{ All traits } & \\
\hline & attractiveness & facial maturity & $\bar{r}$ & \multicolumn{2}{|l|}{$\bar{r}$} & \\
\hline $0^{\circ}-45^{\circ}$ & $0.36 * *$ & $0.78 * * *$ & 0.61 & \multicolumn{2}{|c|}{0.61} & \\
\hline $45^{\circ}-90^{\circ}$ & $0.36 * *$ & $0.73 * * *$ & 0.60 & \multicolumn{2}{|c|}{0.51} & \\
\hline $0^{\circ}-90^{\circ}$ & $0.30 *$ & $0.65 * * *$ & 0.50 & \multicolumn{2}{|c|}{0.47} & \\
\hline
\end{tabular}

Note: $* p<0.05, * * p<0.01, * * * p<0.001$; mean $r$ s are not subject to tests of significance.

Some of these relationships may be stronger than others. That is, although the traits were judged consistently across the three orientations, it is logical that the relationship between judgments made at the full-frontal $\left(0^{\circ}\right)$ and three-quarter $\left(45^{\circ}\right)$ views might be stronger than the relationship between judgments made at the full-frontal and profile $\left(90^{\circ}\right)$ views. We therefore tested the differences in these correlations using meta-analytic comparisons (see Rosenthal and Rosnow 2007). Because our data were based on overlapping samples of participants, each of whom contributed equally to the three orientation-based vectors of scores, we corrected for the dependences in the data using the procedures outlined by Meng et al (1992).

We first calculated the mean correlation for the three comparisons between viewing angles. To do this, we averaged the Fisher's $z$ transforms of each of the correlation coefficients across the seven traits for each of the three perspective comparison pairs: $0^{\circ}: 45^{\circ}, 45^{\circ}: 90^{\circ}$, and $0^{\circ}: 90^{\circ}$. We then converted these three Fisher $z$ scores back into correlation coefficients $(r \mathrm{~s})$ using the inverse of the Fisher transform (these scores are reported in the rightmost column of table 1). Using Meng et al's (1992) correction for dependences, we conducted meta-analytic comparisons of these three $r$ values. These tests showed that the mean relationship between judgments made at $0^{\circ}$ and $45^{\circ}$ was not significantly different from the mean relationship between judgments made at $45^{\circ}$ and $90^{\circ}(Z=0.89, p=0.19)$ or the mean relationship between judgments made at $0^{\circ}$ and $90^{\circ}(Z=1.35, p=0.09)$. Similarly, the relationship between judgments made at $45^{\circ}$ and $90^{\circ}$ was not significantly different from the mean relationship between judgments made at $0^{\circ}$ and $90^{\circ}(Z=0.47, p=0.32)$. These effects did not differ when the personality traits (aggressiveness, competence, dominance, likeability, and trustworthiness; all $Z \mathrm{~s}<|1.43|$, all $p \mathrm{~s}>0.08$ ) and the physiognomic traits (attractiveness and facial maturity; all $Z s<|1.14|$, all $p$ s $>0.13$ ) were examined separately. Thus, participants' judgments were again consistent across all three viewing angles, with no significant increase in magnitude for perspectives with more (ie $0^{\circ}: 45^{\circ}$ ) versus less $\left(\right.$ eg $\left.0^{\circ}: 90^{\circ}\right)$ physical-spatial overlap.

Impressions of traits from faces were therefore consistent across changes in viewing angle. Participants' inferences about the personality and physiognomic characteristics of the men's faces were significantly correlated across full-frontal, three-quarter, and profile viewing angles. In addition, the relationships between judgments made at the various viewing angles were equally strong regardless of which angles were being compared (eg judgments made from perceptions at $0^{\circ}$ were just as well correlated with judgments made from perceptions at $45^{\circ}$ as they were for judgments made from 
perceptions at $90^{\circ}$ ). These findings extend what is known about face-based trait inferences from past work, which has almost exclusively employed faces presented at $0^{\circ}$. Additionally, the present findings extend the ecological validity of that past work, as we rarely have the opportunity in daily life to stare someone straight in the face when forming an impression about her/him. Rather, most of the people we perceive throughout the course of a given day are seen in passing (eg walking to work, riding the bus, or shopping at the market). Although we do not have a great deal of time to perceive these people, we still form impressions about them, and recent work has shown that we may form impressions of others in just a fraction of a second (Bar et al 2006; Rule and Ambady 2008b; Rule et al 2009; Willis and Todorov 2006). As in the majority of work examining trait inferences from faces viewed at self-paced durations, in these time-limited studies the experimenters only tested photographs of targets presented at $0^{\circ}$. In study 2 we therefore sought to extend the ecological validity of the present work further by determining whether these split-second judgments are consistent across orientations of the face.

\section{Study 2}

Study 1 has extended the ecological validity of previous work testing perceptions of traits from faces by demonstrating that judgments made at $0^{\circ}$ agree with those made at $45^{\circ}$ and $90^{\circ}$. Given that many of our perceptions of others do not occur with the luxury of unlimited time, as in study 1, we sought to make these same comparisons across viewing orientations when time was limited to a fraction $(1 / 20$ th) of a second: $50 \mathrm{~ms}$. Thus, in study 2 we repeated the procedures of study 1 but restrained participants' viewing time to $50 \mathrm{~ms}$.

\subsection{Method}

Forty-two undergraduates (twenty-six women; ages 18-22 years) participated for partial credit in an introductory psychology course (fourteen in each condition). Stimuli and procedures were the same as in study 1 with several exceptions. Participants were instructed that they would be seeing each face for only a fraction of a second and were given three practice trials with faces and traits not used in the actual study to acquaint them with the timing of the task. Each face was preceded by a fixation cross for $500 \mathrm{~ms}$ to alert the participant that the target was forthcoming. The face was then shown for $50 \mathrm{~ms}$ and succeeded by a backward mask for $100 \mathrm{~ms}$. The backward mask consisted of a scrambled face, matched with the faces for high and low spatial frequencies.

\subsection{Results and discussion}

Judgments of targets for each trait at each orientation were averaged across participants, following the same analytic procedures as in study 1 (see table A2 in the appendix for trait inter-correlations). The mean judgment for each target was then correlated across orientations by trait (see table 2). For the five personality traits (aggressiveness, competence, dominance, likeability, and trustworthiness), participants' ratings of the faces were significantly correlated between the $0^{\circ}$ and $45^{\circ}$ orientations (all $r \mathrm{~s}>0.30$, all $p \mathrm{~s}<0.05)$ but judgments at $90^{\circ}$ were not related to judgments at either $0^{\circ}$ or $45^{\circ}$ (all $r \mathrm{~s}<|0.21|$, all $p \mathrm{~s}>0.11$ ). For the two physiognomic traits (attractiveness and facial maturity), however, judgments continued to show consistency across all three orientations (all $r \mathrm{~s}>0.27$, all $p \mathrm{~s}<0.05$ ).

As in study 1 , we compared the differences in strength for the relationships between viewing angles by meta-analytically combining the correlation coefficients across the seven traits (overall mean $r$ s are reported in the rightmost column of table 2). Overall, there were no significant differences in magnitude for the comparisons across viewing angles (all $Z \mathrm{~s}<|1.51|$, all $p \mathrm{~s}>0.07$ ), but the personality traits 
Table 2. Correlation coefficients by trait for participants' judgments of targets between $0^{\circ}, 45^{\circ}$, and $90^{\circ}$ viewing orientations following $50 \mathrm{~ms}$ perceptions in study 2 (degrees of freedom $=57$ ).

\begin{tabular}{|c|c|c|c|c|c|c|}
\hline \multirow{2}{*}{$\begin{array}{l}\text { Viewing } \\
\text { orientations }\end{array}$} & \multicolumn{6}{|c|}{ Personality traits } \\
\hline & aggressiveness & competence & dominance & likeability & trustworthiness & $\bar{r}$ \\
\hline \multirow{5}{*}{$\begin{array}{l}0^{\circ}-45^{\circ} \\
45^{\circ}-90^{\circ} \\
0^{\circ}-90^{\circ}\end{array}$} & $0.42 * * *$ & $0.34 * *$ & $0.47 * * *$ & $0.37 * *$ & $0.30 *$ & 0.38 \\
\hline & 0.21 & -0.06 & 0.09 & 0.06 & 0.00 & 0.06 \\
\hline & -0.07 & 0.12 & 0.04 & 0.09 & 0.19 & 0.07 \\
\hline & \multicolumn{3}{|c|}{ Physiognomic traits } & & \multicolumn{2}{|c|}{ All traits } \\
\hline & attractiveness & facial maturity & $\bar{r}$ & & \multicolumn{2}{|c|}{$\bar{r}$} \\
\hline $0^{\circ}-45^{\circ}$ & $0.48 * * *$ & $0.46^{* * *}$ & 0.47 & \multicolumn{2}{|c|}{0.41} & \\
\hline $45^{\circ}-90^{\circ}$ & $0.49 * * *$ & $0.62 * * *$ & 0.56 & \multicolumn{2}{|c|}{0.22} & \\
\hline $0^{\circ}-90^{\circ}$ & $0.27 *$ & $0.50 * * *$ & 0.39 & \multicolumn{2}{|c|}{0.17} & \\
\hline
\end{tabular}

Note: $* p<0.05, * * p<0.01, * * * p<0.001$; mean $r$ s are not subject to tests of significance.

and physiognomic traits showed different patterns. Consistent with the data reported above, the strength of relationship between judgments of personality traits made at $0^{\circ}$ and $45^{\circ}$ was significantly greater than the strength of relationship between judgments made at $45^{\circ}$ and $90^{\circ}(Z=1.82, p=0.03)$ and judgments made at $0^{\circ}$ and $90^{\circ}$ $(Z=1.75, p=0.04)$, with no significant difference between the judgments made at $45^{\circ}$ and $90^{\circ}$ and $0^{\circ}$ and $90^{\circ}(Z=0.08, p=0.47)$. For the physiognomic traits, however, none of these relationships was significantly different (all $Z \mathrm{~s}<|1.41|$, all $p \mathrm{~s}>0.08$ ).

These data therefore suggest that perceptions of personality traits under limited time constraints are consistent between full-frontal and three-quarter perspectives but that neither of these judgments is consistent with judgments of the same faces when seen in profile. This finding is not entirely surprising in light of the previous work that has reported either a three-quarter view 'advantage' in perceiving faces (eg Bruce et al 1987) or a three-quarter view equivalence (to full-frontal views-McKone 2008) in perceiving faces. That is, perceiving a face at a $45^{\circ}$ angle provides much of the information from the full face while also providing some additional information from further back along the face and head. Study 1 showed that participants' impressions from the full-frontal and three-quarter angles agreed with those from profiles when time was unlimited. Thus, restricting exposure time may affect inferences of traits from profile views more than it does when the faces are viewed from full-frontal or threequarter views.

For physiognomic traits - those not requiring social inference but, rather, relying on the structural properties of the face alone - the consistency between views was not impaired by restricting exposure time to $50 \mathrm{~ms}$. This could be because features that underlie physical judgments are easier to perceive than are the features that underlie higher-level, social judgments, or possibly because profiles of faces may be processed more as features or parts than full-frontal views, which may be processed more holistically or as Gestalts (see Rule and Ambady 2008c; Zebrowitz 1997). Another explanation might be that attractiveness and facial maturity are core underlying dimensions in person perception. Indeed, researchers have theorized that attractiveness and facial maturity are particularly important in the perception of human faces and that they both might serve adaptive evolutionary functions (eg Rhodes 2006; Zebrowitz and Montepare 2006). Thus, physiognomic traits led to impressions that were consistent across viewing angles - even under temporally impoverished conditions and despite the variance in the features available to make inferences across views. 
3.2.1 Correlations across studies. Similar to previous researchers (eg Bar et al 2006), we correlated participants' ratings across presentation time as well. Self-paced judgments in study 1 were significantly related to the judgments made following just $50 \mathrm{~ms}$ of exposure in study 2 for the full-frontal and three-quarter perspectives (see table 3 ). This was true for all the traits with the exception of competence, which was only correlated at $45^{\circ}$. Meta-analytic comparisons showed that the mean relationships for judgments made at self-paced and $50 \mathrm{~ms}$ durations were significantly greater at $0^{\circ}$ $(Z=2.60, p=0.005)$ and $45^{\circ}(Z=1.88, p=0.03)$ than at $90^{\circ}$. This was true for the mean effects of both the personality traits $(Z \mathrm{~s}>1.72, p \mathrm{~s}<0.04)$ and physiognomic traits $(Z \mathrm{~s}>2.09, p \mathrm{~s}<0.02)$. The difference between the correlations across time for the $0^{\circ}$ and $45^{\circ}$ views did not significantly differ (all $Z \mathrm{~s}<0.84, p \mathrm{~s}>0.20$ ). Thus, judgments made from faces presented at full-frontal and three-quarter views were similarly correlated across time and both views were significantly better correlated across time than judgments made from faces presented in profile.

Table 3. Correlations across presentation time (self-paced, study 1; $50 \mathrm{~ms}$, study 2) for judgments at each viewing orientation $\left(0^{\circ}, 45^{\circ}\right.$, and $90^{\circ}$; degrees of freedom $\left.=57\right)$.

\begin{tabular}{|c|c|c|c|c|c|c|}
\hline \multirow{2}{*}{$\begin{array}{l}\text { Viewing } \\
\text { orientations }\end{array}$} & \multicolumn{6}{|c|}{ Personality traits } \\
\hline & aggressiveness & competence & dominance & likeability & trustworthiness & $\bar{r}$ \\
\hline \multirow{5}{*}{$\begin{array}{l}0^{\circ} \\
45^{\circ} \\
90^{\circ}\end{array}$} & $0.67 * * *$ & 0.18 & $0.54 * * *$ & $0.47 * * *$ & $0.55 * * *$ & 0.52 \\
\hline & $0.34 * *$ & $0.33 * *$ & $0.60 * * *$ & $0.25 *$ & $0.28 *$ & 0.43 \\
\hline & 0.01 & 0.15 & 0.14 & 0.14 & 0.07 & 0.22 \\
\hline & \multicolumn{3}{|c|}{ Physiognomic traits } & & \multicolumn{2}{|c|}{ All traits } \\
\hline & attractiveness & facial maturity & $\bar{r}$ & & \multicolumn{2}{|c|}{$\bar{r}$} \\
\hline $0^{\circ}$ & $0.42 * * *$ & $0.60 * * *$ & 0.50 & \multicolumn{2}{|c|}{0.50} & \\
\hline $45^{\circ}$ & $0.38 * *$ & $0.47 * * *$ & 0.37 & \multicolumn{2}{|c|}{0.38} & \\
\hline $90^{\circ}$ & $0.32 *$ & 0.12 & 0.10 & \multicolumn{2}{|c|}{0.14} & \\
\hline
\end{tabular}

Note: $* p<0.05, * * p<0.01, * * * p<0.001$; mean $r$ s are not subject to tests of significance.

Interestingly, attractiveness was the only trait showing a significant correlation across the self-paced and $50 \mathrm{~ms}$ exposures when judged at $90^{\circ}$. Given that attractiveness was also judged consistently across all three viewing angles, both at the self-paced and $50 \mathrm{~ms}$ durations, these findings may suggest that the cues to attractiveness are particularly consistent and robust across viewing angle and across time. However, as discussed above, it is not clear whether this is because of perceptual ease, evolutionary salience, or both.

Consistency among judgments across exposure times suggests that the cues leading to judgments at self-paced durations are similar to those leading to judgments at $50 \mathrm{~ms}$ durations. It is therefore not surprising that participants' judgments were correlated across presentation time for those traits that were also correlated across viewing angle in the $50 \mathrm{~ms}$ condition (though this was not true for full-frontal judgments of competence and profile judgments of facial maturity). In some sense, this would be expected and necessary if the same traits allow for the same judgments across both presentation time and viewing angle. For example, if the same facial cues that subserve perceptions of dominance are judged consistently at both $50 \mathrm{~ms}$ and when self-paced, they should necessarily also be consistently judged across viewing angle if the same cues are being used. Naturally, this is sensible for the $0^{\circ}$ and $45^{\circ}$ orientations, which have considerable featural overlap. The cues to profiles might necessarily be distinct, however, because the angle of observation is much more discrepant from that of the other views. 


\section{General discussion}

Throughout the day, we typically perceive a large number of people. Though we may not pause to think much about these perceptions, they influence our impressions and judgments of others (eg Blair et al 2004b). Sometimes these perceptions have serious consequences for both the targets (Blair et al 2004a; Eberhardt et al 2006) and the perceivers (such as in the case of eyewitness testimony-eg MacLin et al 2001).

In nearly all studies of the way we perceive and form impressions of others, researchers have employed face stimuli that display full faces of the target at $0^{\circ}$. In a real-life setting, however, we may be more likely to perceive others at an angle, rather than head-on. In many cases, we enjoy the luxury of perceiving others for long durations; such as when observing a distracted fellow passenger on a commuter train. However, in other cases we are forced to perceive targets' faces quickly. Some of these brief exposures may be innocuous (such as passing someone on the street) but often the briefest perceptions are the most critical (such as observing a robbery at gunpoint).

The current findings show that our judgments when time is unrestricted are consistent across the full-frontal, three-quarter, and profile views of the face. However, when time is limited, we may be less capable of extracting the information necessary to form the same impressions of individuals at profile than we do when perceiving them from full-frontal or three-quarter views. Traits based solely on physical appearance, however, appear to be an exception. Judgments of attractiveness and facial maturity were consistent across the three orientations at both restricted $(50 \mathrm{~ms})$ and unrestricted (self-paced) durations.

In previous work, Bar et al (2006) reported that judgments of threat from faces (a perception important for survival) were judged consistently between durations of $39 \mathrm{~ms}$ and $1700 \mathrm{~ms}$, whereas judgments of intelligence were not. Though this may support the argument that attractiveness and facial maturity are, like threat, more basic to human survival than are higher-level social qualities, like competence or intelligence (see also Rhodes 2006; Zebrowitz and Montepare 2006), it may also be that the presentation of threat, attractiveness, and facial maturity have better-defined physical features, facilitating their perception. Further research would be needed to disentangle the relationship of such factors, or to determine whether they are analogous (eg threat and attractiveness might have well-defined physical features because they are evolutionarily adaptive).

Judgments were also correlated across presentation time for most traits. With the exception of competence at $0^{\circ}$, self-paced perceptions were significantly correlated with $50 \mathrm{~ms}$ perceptions for all seven traits at $0^{\circ}$ and $45^{\circ}$. Judgments of attractiveness from profiles were also correlated across the two durations. This is particularly interesting, given that bilateral symmetry in faces may contribute to their perceived attractiveness (eg Jones et al 2001; Rhodes 2006; Thornhill and Gangestad 1993). Although judgments of bilateral symmetry may be easily extracted from full-frontal (and possibly also three-quarter) views of the face, judgments of facial symmetry from profiles would be difficult or impossible because only a single half of the face is present. Future work may therefore seek to explore whether the features contributing to judgments of attractiveness at full-frontal views are the same as those judged at three-quarter and profile views. For instance, the relative contribution of bilateral symmetry at the fullfrontal orientation may be greater than when the face is perceived from other angles. Thus, relative contributions between symmetry, averageness, and perceptions of health (see Rhodes 2006), for example, may shift as the perceiver's viewpoint is changed.

Previous work has shown that judgments from full faces are consistent (Ballew and Todorov 2007) and accurate (Rule and Ambady 2008b) at $50 \mathrm{~ms}$. The current findings are in accord with that prior work but add the novel insight that judgmental consistency may be extended from just full-frontal views of faces to the three-quarter 
view at the previously-documented temporal boundary of $50 \mathrm{~ms}$. Perhaps more critically, however, the current findings also demonstrate that when time is unrestricted, judgments at all three orientations $\left(0^{\circ}, 45^{\circ}\right.$, and $\left.90^{\circ}\right)$ are consistent. Notably, this was also true for physiognomic judgments (ie attractiveness and facial maturity) at $50 \mathrm{~ms}$.

In sum, these findings contribute to the theoretical literature on person perception and impression formation, as well as to the applied literature on person recognition, such as research on eyewitness testimony. Trait inferences from faces agree across perceivers' viewing angles of men's faces, but only physiognomic traits remain consistent when time is restricted to near-subliminal levels. Thus, perceptions from faces under spatially and temporally limited conditions can be both expedient and robust.

Acknowledgments. This research was supported in part by a National Science Foundation research grant to Nalini Ambady (NSF BCS-0435547) and a National Science Foundation graduate fellowship to Nicholas O Rule. We would like to thank Jay Conner for volunteering the example photograph.

\section{References}

Albright L, Malloy T E, Dong Q, Kenny D A, Fang X, Winquist L, Yu D, 1997 "Cross-cultural consensus in personality judgments" Journal of Personality and Social Psychology $72558-569$

Ambady N, Bernieri F J, Richeson J A, 2000 "Toward a histology of social behavior: Judgmental accuracy from thin slices of the behavioral stream", in Advances in Experimental Social Psychology volume 32, Ed. M P Zanna (New York: Academic Press) pp 201-271

Ballew C C II, Todorov A, 2007 "Predicting political elections from rapid and unreflective face judgments" Proceedings of the National Academy of Sciences of the USA 10417948 - 17953

Bar M, Neta M, Linz H, 2006 "Very first impressions" Emotion 6 269-278

Bargh J, 1994 "The four horsemen of automaticity: Awareness, efficiency, intention, and control in social cognition", in Handbook of Social Cognition 2nd edition, Eds J R S Wyer, T K Srull (Hillsdale, NJ: Lawrence Erlbaum Associates) pp 1-40

Berry D S, Landry J C, 1997 "Facial maturity and daily social interaction" Journal of Personality and Social Psychology $72570-580$

Berry D S, McArthur L Z, 1985 "Some components and consequences of a babyface" Journal of Personality and Social Psychology $48312-323$

Blair I V, Judd C M, Chapleau K M, 2004a "The influence of Afrocentric facial features in criminal sentencing" Psychological Science 15 674-679

Blair I V, Judd C M, Fallman J L, 2004b "The automaticity of race and Afrocentric facial features in social judgments" Journal of Personality and Social Psychology 87 763-778

Bruce V, Valentine T, Baddeley A, 1987 "The basis of the 3/4 view advantage in face recognition" Applied Cognitive Psychology $1109-120$

Busey T A, Zaki S R, 2004 "The contribution of symmetry and motion to the recognition of faces at novel orientations" Memory \& Cognition 32 916-931

Chiao J Y, Adams R B Jr, Tse P U, Lowenthal W T, Richeson J A, Ambady N, 2008 "Knowing who's boss: fMRI and ERP investigations of social dominance perception" Group Processes \& Intergroup Relations $11202-214$

Clifford M M, Walster E, 1973 "Research note: The effect of physical attractiveness on teacher expectations" Sociology of Education $46248-258$

Dion K, Berscheid E, Walster E, 1972 "What is beautiful is good" Journal of Personality and Social Psychology $24285-290$

Eberhardt J L, Davies P G, Purdie-Vaughns V J, Johnson S L, 2006 "Looking deathworthy: Perceived stereotypicality of Black defendants predicts capital-sentencing outcomes" Psychological Science $17383-386$

Griffin A M, Langlois J H, 2006 "Stereotype directionality and attractiveness stereotyping: Is beauty good or is ugly bad?" Social Cognition $24187-206$

Hess U, Adams R B Jr, Kleck R E, 2005 "Who may frown and who should smile? Dominance, affiliation, and the display of happiness and anger" Cognition and Emotion 19 515-536

Hill H, Bruce V, 1996 "The effects of lighting on the perception of facial surfaces" Journal of Experimental Psychology: Human Perception and Performance 22 986-1004

Hill H, Schyns P G, Akamatsu S, 1997 "Information and viewpoint dependence in face recognition" Cognition $62201-222$

Jones B C, Little A C, Penton-Voak I S, Tiddeman B P, Burt D M, Perrett D I, 2001 "Facial symmetry and judgements of apparent health: Support for a 'good genes' explanation of the attractiveness - symmetry relationship" Evolution and Human Behavior 22 417-429 
Langlois J H, Kalakanis L, Rubenstein A J, Larsen A, Hallam M, Smoot M, 2000 "Maxims or myths of beauty? A meta-analytic and theoretical review" Psychological Bulletin 126 390-423

Leeuwen M L van, Macrae C N, 2004 "Is beautiful always good? Implicit benefits of facial attractiveness" Social Cognition 22637 -649

McKone E, 2008 "Configural processing and face viewpoint" Journal of Experimental Psychology: Human Perception and Performance $34310-327$

MacLin O H, MacLin M K, Malpass R S, 2001 "Race, arousal, attention, exposure and delay: An examination of factors moderating face recognition" Psychology, Public Policy, and Law $7134-152$

Mazur A, 2005 Biosociology of Dominance and Deference (New York: Rowman \& Littlefield)

Meng X L, Rosenthal R, Rubin D B, 1992 "Comparing correlated correlation coefficients" Psychological Bulletin 111 172-175

O'Toole A J, Edelman S, Bülthoff H H, 1998 "Stimulus-specific effects in face recognition over changes in viewpoint" Vision Research $382351-2363$

Patterson K E, Baddeley A D, 1977 "When face recognition fails" Journal of Experimental Psychology: Human Learning and Memory $3406-417$

Porter S, England L, Juodis M, Brinke L ten, Wilson K, 2008 "Is the face a window to the soul? Investigating the accuracy of intuitive judgments of the trustworthiness of human faces" Canadian Journal of Behavioral Science 40171 - 177

Rhodes G, 2006 "The evolutionary psychology of facial beauty" Annual Review of Psychology 57 $199-226$

Rosenthal R, Rosnow R L, 2007 Essentials of Behavioral Research: Methods and Data Analysis 3rd edition (Boston, MA: McGraw-Hill)

Rule N O, Ambady N, 2008a "The face of success: Inferences from chief executive officers" appearance predict company profits" Psychological Science $19109-111$

Rule N O, Ambady N, 2008b "Brief exposures: Male sexual orientation is accurately perceived at 50 ms" Journal of Experimental Social Psychology $441100-1105$

Rule N O, Ambady N, 2008c "First impressions: Peeking at the neural underpinnings", in First Impressions Eds N Ambady, J J Skowronski (New York: Guilford) pp 35-56

Rule N O, Ambady N, 2009 "She's got the look: Inferences from female chief executive officers' faces predict their success" Sex Roles (doi:10.1007/s11199-009-9658-9)

Rule N O, Ambady N, Hallett K C, 2009 "Female sexual orientation is perceived accurately, rapidly, and automatically from the face and its features" Journal of Experimental Social Psychology (doi:10.1016/j.jesp.2009.07.010)

Thornhill R, Gangestad S W, 1993 "Human facial beauty: Averageness, symmetry, and parasite resistance" Human Nature $4237-269$

Todorov A, Mandisodza A N, Goren A, Hall C C, 2005 "Inferences of competence from faces predict election outcomes" Science $\mathbf{3 0 8} 1623-1626$

Willis J, Todorov A, 2006 "First impressions: Making up your mind after a 100-ms exposure to a face" Psychological Science $17592-598$

Zebrowitz L A, 1997 Reading Faces: Window to the Soul? (Boulder, CO: Westview)

Zebrowitz L A, Brownlow S, Olson K, 1992 "Baby talk to the babyfaced" Journal of Nonverbal Behavior $16143-158$

Zebrowitz L A, Montepare J M, 1992 "Impressions of babyfaced individuals across the life span" Developmental Psychology $281143-1152$

Zebrowitz L A, Montepare J M, 2006 "The ecological approach to person perception: Evolutionary roots and contemporal offshoots", in Evolution and Social Psychology Eds M Schaller, J A Simpson, D T Kenrick (New York: Psychology Press) pp $81-113$

Zebrowitz L A, Montepare J M, Lee H K, 1993 “They don’t all look alike: Individuated impressions of other racial groups" Journal of Personality and Social Psychology 65 85-101 


\section{Appendix 1}

Table A1. Inter-correlations between the seven traits rated at participants' own pace in study 1 .

\begin{tabular}{|c|c|c|c|c|c|c|c|}
\hline \multirow[t]{2}{*}{ Orientation } & \multirow[t]{2}{*}{ Trait } & \multicolumn{6}{|l|}{ Trait } \\
\hline & & 2 & 3 & 4 & 5 & 6 & 7 \\
\hline $0^{\circ}$ & $\begin{array}{l}\text { 1. Attractiveness } \\
\text { 2. Aggressiveness } \\
\text { 3. Competence } \\
\text { 4. Dominance } \\
\text { 5. Likeability } \\
\text { 6. Facial maturity } \\
\text { 7. Trustworthiness }\end{array}$ & -0.09 & $\begin{array}{l}0.61 * * * \\
-0.29 *\end{array}$ & $\begin{array}{l}0.00 \\
0.81 * * * \\
-0.08\end{array}$ & $\begin{array}{r}0.68 * * * \\
-0.55 * * * \\
0.81 * * * \\
-0.37 * *\end{array}$ & $\begin{array}{l}-0.19 \\
0.52 * * * \\
0.05 \\
0.63 * * * \\
-0.27 *\end{array}$ & $\begin{array}{r}0.74 * * * \\
-0.52 * * * \\
0.79 * * * \\
-0.34 * * \\
0.93 * * * \\
-0.29 *\end{array}$ \\
\hline $45^{\circ}$ & $\begin{array}{l}\text { 1. Attractiveness } \\
\text { 2. Aggressiveness } \\
\text { 3. Competence } \\
\text { 4. Dominance } \\
\text { 5. Likeability } \\
\text { 6. Facial maturity } \\
\text { 7. Trustworthiness }\end{array}$ & 0.05 & $\begin{array}{l}0.58 * * * \\
-0.25\end{array}$ & $\begin{array}{l}0.30 * \\
0.72 * * * \\
0.20\end{array}$ & $\begin{array}{c}0.65 * * * \\
-0.40 * * \\
0.75 * * * \\
0.02\end{array}$ & $\begin{array}{l}0.02 \\
0.41 * * \\
0.25 \\
0.64 * * * \\
0.06\end{array}$ & $\begin{array}{l}0.58 * * * \\
-0.47 * * * \\
0.73 * * * \\
-0.08 \\
0.86 * * * \\
0.01\end{array}$ \\
\hline $90^{\circ}$ & $\begin{array}{l}\text { 1. Attractiveness } \\
\text { 2. Aggressiveness } \\
\text { 3. Competence } \\
\text { 4. Dominance } \\
\text { 5. Likeability } \\
\text { 6. Facial maturity } \\
\text { 7. Trustworthiness }\end{array}$ & 0.04 & $\begin{array}{l}0.55^{* * *} \\
-0.16\end{array}$ & $\begin{array}{l}0.27 * \\
0.67 * * * \\
0.20\end{array}$ & $\begin{array}{l}0.72 * \\
-0.20 \\
0.68 * \\
0.18\end{array}$ & $\begin{array}{l}-0.08 \\
0.26 * \\
0.28 * \\
0.56 * * * \\
0.12\end{array}$ & $\begin{array}{l}0.70 * * * \\
-0.11 \\
0.62 * * * \\
0.12 \\
0.83 * * * \\
0.07\end{array}$ \\
\hline
\end{tabular}

Note: $* p<0.05, * * p<0.01, * * p<0.001$.

Table A2. Inter-correlations between the seven traits rated following $50 \mathrm{~ms}$ of presentation time in study 2 .

\begin{tabular}{|c|c|c|c|c|c|c|c|}
\hline \multirow[t]{2}{*}{ Orientation } & \multirow[t]{2}{*}{ Trait } & \multicolumn{6}{|l|}{ Trait } \\
\hline & & 2 & 3 & 4 & 5 & 6 & 7 \\
\hline $0^{\circ}$ & $\begin{array}{l}\text { 1. Attractiveness } \\
\text { 2. Aggressiveness } \\
\text { 3. Competence } \\
\text { 4. Dominance } \\
\text { 5. Likeability } \\
\text { 6. Facial maturity } \\
\text { 7. Trustworthiness }\end{array}$ & $-0.28^{*}$ & $\begin{array}{r}0.23 \\
-0.02\end{array}$ & $\begin{array}{l}-0.28 * \\
0.68 * * * \\
0.15\end{array}$ & $\begin{array}{l}0.55^{* * *} \\
-0.42^{* * *} \\
0.04 \\
-0.46^{* * *}\end{array}$ & $\begin{array}{c}-0.40 * * \\
0.57 * * * \\
0.19 \\
0.53 * * * \\
-0.40^{* *}\end{array}$ & $\begin{array}{c}0.54 \text { *** } \\
-0.47 * * * \\
0.16 \\
-0.35^{* *} \\
0.55^{* * *} \\
-0.24\end{array}$ \\
\hline $45^{\circ}$ & $\begin{array}{l}\text { 1. Attractiveness } \\
\text { 2. Aggressiveness } \\
\text { 3. Competence } \\
\text { 4. Dominance } \\
\text { 5. Likeability } \\
\text { 6. Facial maturity } \\
\text { 7. Trustworthiness }\end{array}$ & -0.24 & $\begin{array}{l}0.26^{*} \\
0.01\end{array}$ & $\begin{array}{l}-0.21 \\
0.62 * * * \\
0.04\end{array}$ & $\begin{array}{c}0.36^{* *} \\
-0.39 * * \\
0.29 * \\
-0.47 * * *\end{array}$ & $\begin{array}{l}-0.46 * * * \\
0.28 * \\
0.01 \\
0.47 * * * \\
-0.24\end{array}$ & $\begin{array}{l}0.28^{*} \\
-0.34 * * \\
0.27 * \\
-0.40^{* *} \\
0.38 * * \\
-0.19\end{array}$ \\
\hline $90^{\circ}$ & $\begin{array}{l}\text { 1. Attractiveness } \\
\text { 2. Aggressiveness } \\
\text { 3. Competence } \\
\text { 4. Dominance } \\
\text { 5. Likeability } \\
\text { 6. Facial maturity } \\
\text { 7. Trustworthiness }\end{array}$ & -0.05 & $\begin{array}{r}-0.09 \\
0.23\end{array}$ & $\begin{array}{l}0.10 \\
0.51 \text { *** } \\
0.22\end{array}$ & $\begin{array}{c}0.44^{* * * *} \\
-0.08 \\
0.13 \\
-0.01\end{array}$ & $\begin{array}{c}-0.33^{*} \\
0.20 \\
0.19 \\
0.30 * \\
-0.34 * *\end{array}$ & $\begin{array}{l}0.43^{* * *} \\
0.12 \\
0.37 * * \\
0.19 \\
0.40^{* *} \\
-0.10\end{array}$ \\
\hline
\end{tabular}

Note: $* p<0.05, * * p<0.01, * * * p<0.001$. 


\section{PERTEPTION}

VOLUME 382009

www.perceptionweb.com

Conditions of use. This article may be downloaded from the Perception website for personal research by members of subscribing organisations. Authors are entitled to distribute their own article (in printed form or by e-mail) to up to 50 people. This PDF may not be placed on any website (or other online distribution system) without permission of the publisher. 